\title{
Peripheral blood cytokine responses and disease severity in respiratory syncytial virus bronchiolitis
}

\author{
L. Bont*, C.J. Heijnen*, A. Kavelaars*, W.M.C. van Aalderen", F. Brus ${ }^{\S}$, J.Th.M. Draaisma ${ }^{+}$, \\ S.M. Geelen*, H.J. van Vught*, J.L.L. Kimpen*
}

Peripheral blood cytokine responses and disease severity in respiratory syncytial virus bronchiolitis. L. Bont, C.J. Heijnen, A. Kavelaars, W.M.C van Aalderen, F. Brus, J.Th.M. Draaisma, S.M. Geelen, H.J. van Vught, J.L.L. Kimpen. (C)RS Journals Ltd 1999.

ABSTRACT: The role of cellular immunity in disease severity in respiratory syncytial virus (RSV) bronchiolitis is largely unknown. This study investigated the association between disease severity and systemic cytokine responses in hospitalized ventilated and nonventilated RSV bronchiolitis patients.

In whole blood cultures stimulated with phytohaemagglutinin (PHA), lymphoproliferative responses and interferon (IFN)- $\gamma$ and interleukin (IL)-4 production during acute illness were measured. In addition, plasma cytokines were measured. Measurements were repeated in the convalescent phase, 3-4 weeks after admission.

Fifty patients were included. The median age in ventilaled patients was significantly lower than in nonventilated patients $(1$ versus 4 months, $p<0.05)$. In comparison with nonventilated patients, the ventilated patients had significantly lower lymphoproliferative responses and a lower production of IFN- $\gamma$ and IL-4. In fact, IFN- $\gamma$ and IL-4 production in ventilated patients was almost completely undetectable. Plasma IL-8 levels in ventilated patients were significantly higher than in nonventilated patients. In the convalescent phase, lymphoproliferative and cytokine responses as well as plasma IL-8 levels were normal in both patient groups. Since RSV bronchiolitis is associated with the subsequent development of asthma, the possible skewing of the T-helper (Th1/Th2) cytokine balance was investigated. This was found neither in the acute nor in the convalescent phase.

In conclusion, the data indicate that depressed lymphocyte function and elevated plasma interleukin-8 levels are markers of severe disease. It is suggested that age and maturation related immune mechanisms could explain the occurrence of severe respiratory syncytial virus bronchiolitis requiring mechanical ventilation in young infants.

Eur Respir J 1999; 14: 144-149.
*University Hospital for Children and Youth "Het Wilhelmina Kinderziekenhuis", Utrecht, " Academic Medical Center, Amsterdam, ${ }^{5}$ Dept of Pediatrics, Elisabeth Hospital, Tilburg, ${ }^{+}$Dept of Pediatrics, Rijnstate Hospital, Arnhem, the Netherlands.

\section{Correspondence: J.L.L. Kimpen}

Dept of Pediatric Infectious Diseases

University Hospital for children and youth "Het Wilhelmina Kinderzieckenhuis" POB 18009

3501 CA Utrecht

The Netherlands

Fax: 310302320707

Keywords: Cytokines

disease severity

respiratory syncytial virus

Received: December 91998

Accepted after revision May 181999

This study was funded by the Dutch Asthma Foundation (grant No. 32.96.08)
Respiratory syncytial virus (RSV) bronchiolitis accounts for a considerable number of paediatric intensive care admissions during yearly winter epidemics. Risk factors predicting a complicated course in RSV lower respiratory tract illness, eventually necessitating ventilatory support, include congenital heart disease, prematurity, age $<6$ weeks and chronic lung disease [1-3].

Although knowledge of the immunopathogenesis of RSV bronchiolitis has improved over previous decades, little is known about the association between immunological parameters and disease severity $[4,5]$. To the authors' knowledge, RSV-specific immunoglobulin ( $\mathrm{Ig}) \mathrm{E}$ titres, histamine release and eosinophil cationic protein titres in respiratory secretions and eosinophil blood counts are the only immunological phenomena associated with disease severity $[6,7]$.

Cellular immunity is the classical defence mechanism against viral infections. However, the role of cellular immunity in the immunopathogenesis of RSV bronchiolitis is unclear. In murine models, cytotoxic T-cells have been associated with both clearance of the virus from the lungs and augmentation of lung pathology $[8,9]$. Other studies have suggested that CD4 cells are required for the development of immune mediated lung disease in RSV infected $\mathrm{BALB} / \mathrm{c}$ mice [10]. In the human population even less is known about cellular immunity in RSV infection than in animal models.

Virus-specific cytotoxicity has been demonstrated in primary acute infections and appeared to be an important parameter in recovery [11]. Furthermore, it has been suggested that in RSV-infected patients with lower respiratory tract symptoms, lymphoproliferative responses to phytohaemagglutinin (PHA) are depressed, as are interleukin (IL)- 4 , interferon (IFN)- $\alpha$ and IFN- $\gamma$ production in vitro [12-14]. In particular, these depressed lymphocyte functions suggest that suboptimal cellular immunity might play a role in the outcome of RSV infections. However, thus far no association has been demonstrated between cell-mediated immune responses and disease severity.

RSV bronchiolitis has been related to the subsequent development of asthma [15]. WELLIVER and coworkers [6, 16] showed that RSV can induce virus-specific IgE, which correlates with recurrent episodes of wheezing 
after RSV infection. More recently it has been shown that subjects with asthma have increased release of T-helper (Th) 2 cytokines, including IL-4, and normal or low production of the Th1 cytokine IFN- $\gamma$ [17]. Increased IL-4/ IFN- $\gamma$ ratios have also been mentioned in RSV infection and could therefore explain the association between RSV infection and the subsequent development of asthma [13].

This study compared lymphoproliferative and cytokine responses in ventilated and nonventilated children admitted with RSV bronchiolitis in order to determine a possible role for cellular immunity in disease severity. In addition, the possible skewing of the Th1/Th2 cytokine balance in the course of the disease was investigated.

\section{Methods}

\section{Selection of patients}

Children were included during one winter epidemic in four hospitals in the Netherlands (Wilhelmina Children's Hospital, Utrecht; Beatrix Children's Hospital, Groningen; St. Elisabeth Hospital, Tilburg; Rijnstate Hospital, Arnhem). Inclusion criteria were hospital admission, lower respiratory tract symptoms, age $<13$ months and positive direct immunofluorescence for RSV. Patients with severe illness and nonsevere illness were distinguished by the need for mechanical ventilation. Control children aged $<13$ months without evidence of allergy or infection were selected for this study during the same winter season. Included were infants prior to minor surgery, prior to cardiac surgery in the absence of haemodynamic compromise, healthy prematurely born infants, healthy infants screened for congenital disorders and infants with mild anaemia. This study was approved by the Medical Ethical Committee in all participating centres and parents of all subjects gave written informed consent.

\section{Collection of materials}

Within $24 \mathrm{~h}$ after admission, venous or arterial blood was taken from all patients. From all subjects, blood was obtained in tubes containing ethylenediaminetetraacetic acid (EDTA). Tubes were directly placed on ice, plasma was separated and stored at $-70^{\circ} \mathrm{C}$. In addition, white cell counts were performed (Technicon H1, Bayer Technicon, NY, USA). From subjects in the Wilhelmina Children's Hospital, Utrecht, heparinized blood was taken simultaneously. Three weeks later, in the convalescent phase, heparinized blood and plasma were taken from all subjects.

\section{Cell cultures}

Heparinized blood $(0.5 \mathrm{~mL})$ was diluted in $4.5 \mathrm{~mL}$ Roswell Park Memorial Institute (RPMI) 1640 medium (Life Technologies, Grand Island, NY, USA) and whole blood cultures were performed. Cultures were performed in quadruplicate in 96-well culture plates (Nunc International, Roskilde, Denmark) in the presence of PHA (50 $\mu \mathrm{g} \cdot \mathrm{mL}^{-1}$ ) for $48 \mathrm{~h}$ at $37^{\circ} \mathrm{C}$ with $5 \% \mathrm{CO}_{2}$. Pooled supernatants were kept at $-70^{\circ} \mathrm{C}$. Subsequently, lymphocytes were pulsed with $9.25 \mathrm{kBq}{ }^{3} \mathrm{H}$-thymidine for $18 \mathrm{~h}$ and thymidine incorporation was measured (lymphoproliferative response).

\section{Cytokine assays}

In plasma, IL-4, IL-8, IL-12 and IFN- $\gamma$ were measured. In supernatants, IL- 4 and IFN- $\gamma$ were measured. Concentrations of IL-4 (supernatants), IL-8 and IFN- $\gamma$ (plasma and supernatants) were determined using enzyme-linked immunosorbent assay (ELISA) kits supplied by the Dutch Laboratory for Blood Transfusion (Amsterdam, the Netherlands); the detection limit for IL-4 was $4.7 \mathrm{pg} \cdot \mathrm{mL}^{-1}$, for IL-8 $2.5 \mathrm{pg} \cdot \mathrm{mL}^{-1}$ and for IFN- $\gamma 25 \mathrm{pg} \cdot \mathrm{mL}^{-1}$. Plasma concentrations of IL-4 and IL-12 were determined using "high sensitivity" ELISA kits from Research and Development (Oxon, UK); the detection limit for IL-4 was 1.0 $\mathrm{pg} \cdot \mathrm{mL}^{-1}$ and for IL-12 $0.78 \mathrm{pg} \cdot \mathrm{mL}^{-1}$. When cytokines were not detectable, the minimum detectable level was used in the calculations.

\section{Statistical analysis}

Lymphoproliferative responses are expressed as mean \pm SEM. The Mann-Whitney U-test was used to compare median age of all subjects and of ventilated and nonventilated patients. The Chi-squared test was used to compare relative proportions of prematurely born children. One-way analysis of variance (ANOVA) was used to compare lymphoproliferative responses. Cytokine levels were analysed by one-way ANOVA after logarithmic transformation. If one-way ANOVA analysis showed significant differences, unpaired t-tests using Bonferroni correction were performed in order to analyse which groups have significantly different values and to calculate p-values. Pearson's correlation coefficient was used to evaluate the relation between age and lymphoproliferative responses and cytokine responses.

\section{Results}

\section{Study subjects}

Characteristics of patients and control subjects are shown in table 1 . A total of 50 patients were studied; 27 subjects were admitted to Wilhelmina Children's Hospital and 23 to one of the other hospitals. Twenty-nine (58\%) were male, median age 3 months. Fourteen (28\%) subjects needed mechanical ventilation. The median age of ventilated patients was 1 month, and nonventilated patients 4 months $(\mathrm{p}<0.05)$. Eleven $(22 \%)$ patients, including three pairs of twins, were born prematurely (gestational age 29 4/7-36 5/7 weeks). Eight of these required ventilatory support, whereas in one of these children chronic lung disease was diagnosed. None of the patients had cardiac disease. None of the patients received ribavirin or systemic corticosteroids. All patients survived. Twenty-seven control subjects were included, median age 4 months. Sixty-three per cent were males. Two control subjects were born prematurely.

\section{Cytokine levels in plasma}

Plasma IL-8 levels were measured in 50 patients and 27 control subjects. In the acute phase, IL-8 levels were detectable in $48(96 \%)$ patients and in $25(93 \%)$ control subjects. Plasma IL-8 levels in both ventilated and nonventilated patients were higher than in controls $(p<0.001)$ (fig. 1). In ventilated patients, IL-8 levels were higher than nonventilated patients $(\mathrm{p}<0.01)$. IL-8 levels in the convalescent phase were not significantly different 
Table 1. - Study population characteristics

\begin{tabular}{|c|c|c|c|c|}
\hline & \multicolumn{3}{|c|}{ Patients } & \multirow{2}{*}{$\begin{array}{l}\text { Control } \\
\text { subjects }\end{array}$} \\
\hline & Ventilated & Nonventilated & Total & \\
\hline Subjects n & 14 & 36 & 50 & 27 \\
\hline Age months ${ }^{+}$ & $1(0-11)$ & $4(0-12)^{*}$ & $3(0-12)$ & $4(0-12)$ \\
\hline Male/female & $10 / 4$ & $19 / 17$ & $29 / 21$ & $17 / 10$ \\
\hline $\begin{array}{l}\text { Prematurely } \\
\text { born }\end{array}$ & 8 & $3 *$ & 11 & 2 \\
\hline
\end{tabular}

from controls. IL-4, IL-12 and IFN- $\gamma$ levels in plasma were below the detection level.

Lymphoproliferative response of phytohaemagglutininstimulated whole blood cultures

White blood cell counts, and relative and absolute lymphocyte numbers of ventilated patients did not differ significantly from nonventilated patients, although absolute lymphocyte numbers in ventilated patients tended to be lower than in nonventilated patients $\left(3 \times 10^{9}\right.$ versus $4.2 \times 10^{9}$ cells $\left.\cdot \mathrm{L}^{-1}\right)$. Lymphoproliferative responses in the acute phase are shown in fig. 2. Mean lymphoproliferative responses in ventilated patients and nonventilated patients were lower than in controls $(14,000 \pm 2,500$ and $29,000 \pm$ 4,500 versus $42,000 \pm 2,800$ counts per minute $(\mathrm{cpm})$, $\mathrm{p}<0.001)$. Lymphoproliferative responses in ventilated patients were lower than in nonventilated patients $(\mathrm{p}<$ 0.005). In the convalescent phase, lymphoproliferative responses returned to normal values in both ventilated and nonventilated patients.

Age was related to lymphoproliferative responses in the control infants, although no association was found (data not shown).

\section{Cytokine production in phytohaemagglutinin-stimulated} whole blood cultures

Levels of IL-4 and IFN- $\gamma$ in the acute phase from supernatants of PHA stimulated whole blood cultures are shown in figure 3 . In ventilated patients, IFN- $\gamma$ and IL-4

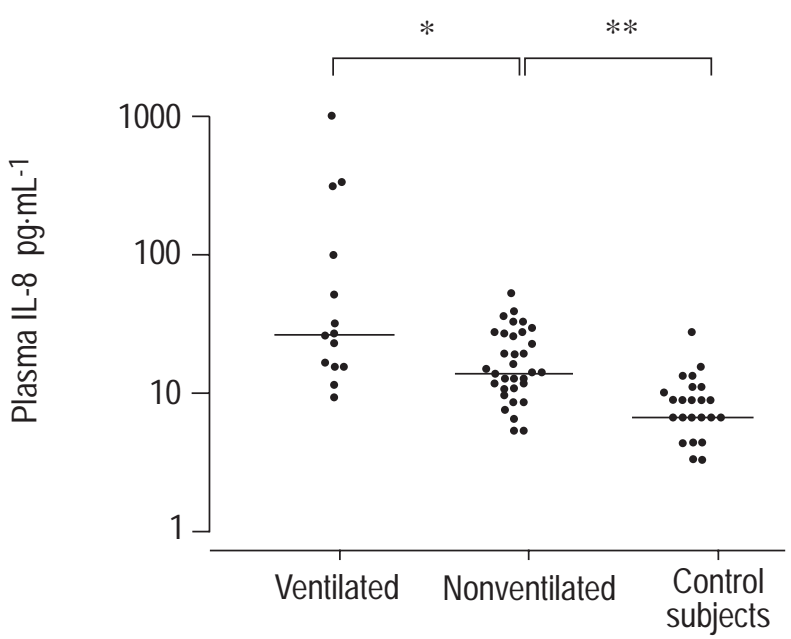

Fig. 1. - Plasma interleukin (IL)-8 levels measured within $24 \mathrm{~h}$ after admission in ventilated patients, nonventilated patients and control subjects. Bars represent mean values. *: $\mathrm{p}<0.01 ; * *$ : $<<0.001$.

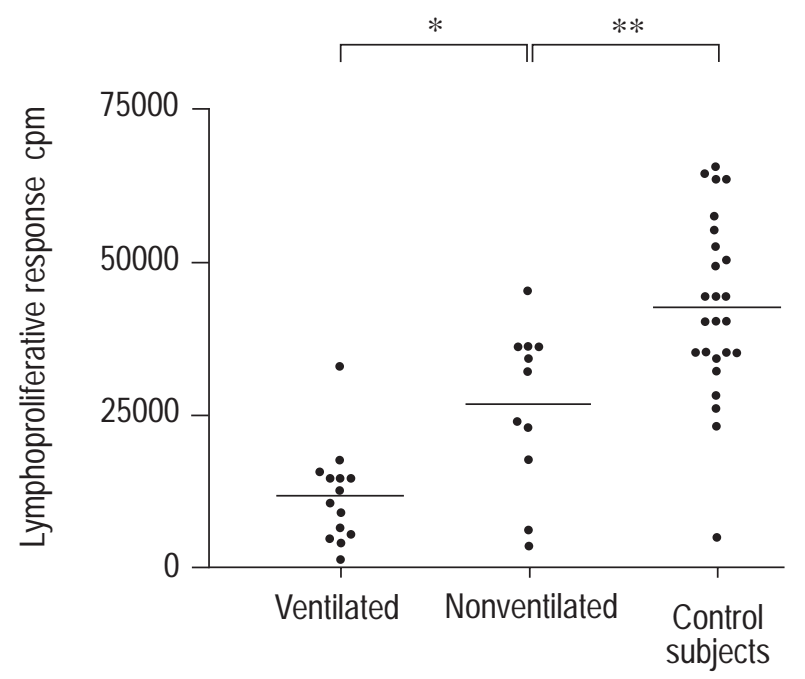

Fig. 2. - Lymphoproliferative responses induced by phytohaemagglutinin measured within $24 \mathrm{~h}$ after admission of ventilated patients, nonventilated patients and control subjects. Bars represent mean values. cpm: counts per minute. $*$ : $\mathrm{p}<0.005 ; * *$ : $\mathrm{p}<0.001$.

levels were below the detection level in 11 out of 13 cases (85\%); in nonventilated patients and in control subjects cytokine levels could be measured in all samples ( $\mathrm{p}<$ 0.001 ). No significant differences were found between nonventilated patients and control subjects for both IFN- $\gamma$ and IL-4. In the convalescent phase, IFN- $\gamma$ and IL-4 levels were normal in both patient groups.

Age was related to IL- 4 and IFN- $\gamma$ responses in control infants (data not shown). Age was not associated with IL-4 responses, but a positive correlation was found between age and IFN $-\gamma$ responses $(\mathrm{r}=0.52, \mathrm{p}<0.01)$. However, nearly all IFN- $\gamma$ responses in ventilated patients were below the minimum IFN- $\gamma$ response found in nonventilated patients and control infants. IL-4/IFN- $\gamma$ ratios in the acute phase in ventilated patients could not be determined, since in practically all patients IL-4 and/or IFN- $\gamma$ levels were below the detection level. IL-4/IFN- $\gamma$ ratios in nonventilated patients were not significantly different from controls. In the convalescent phase, IL-4/IFN- $\gamma$ ratios remained normal.

\section{Discussion}

In this study, IL-8 plasma levels, lymphoproliferative responses and lymphocyte cytokine responses in vitro were associated with disease severity in hospitalized patients with RSV bronchiolitis. Lymphoproliferative responses during acute disease are lower in ventilated patients than in nonventilated patients. Most striking is the almost completely negative response of IFN- $\gamma$ and IL-4 in ventilated patients. In the convalescent phase plasma IL-8, lymphoproliferative responses and cytokine responses normalize in both ventilated and nonventilated patients.

Young age and prematurity appeared to be important factors in determining disease severity. The median age of the ventilated patients was significantly lower than that of the nonventilated patients; except for one patient, all ventilated patients were $<3$ months old. Furthermore, it was found that more ventilated patients than nonventilated patients were born prematurely. Both young age and premature birth are known risk factors for the development of severe bronchiolitis [18]. 

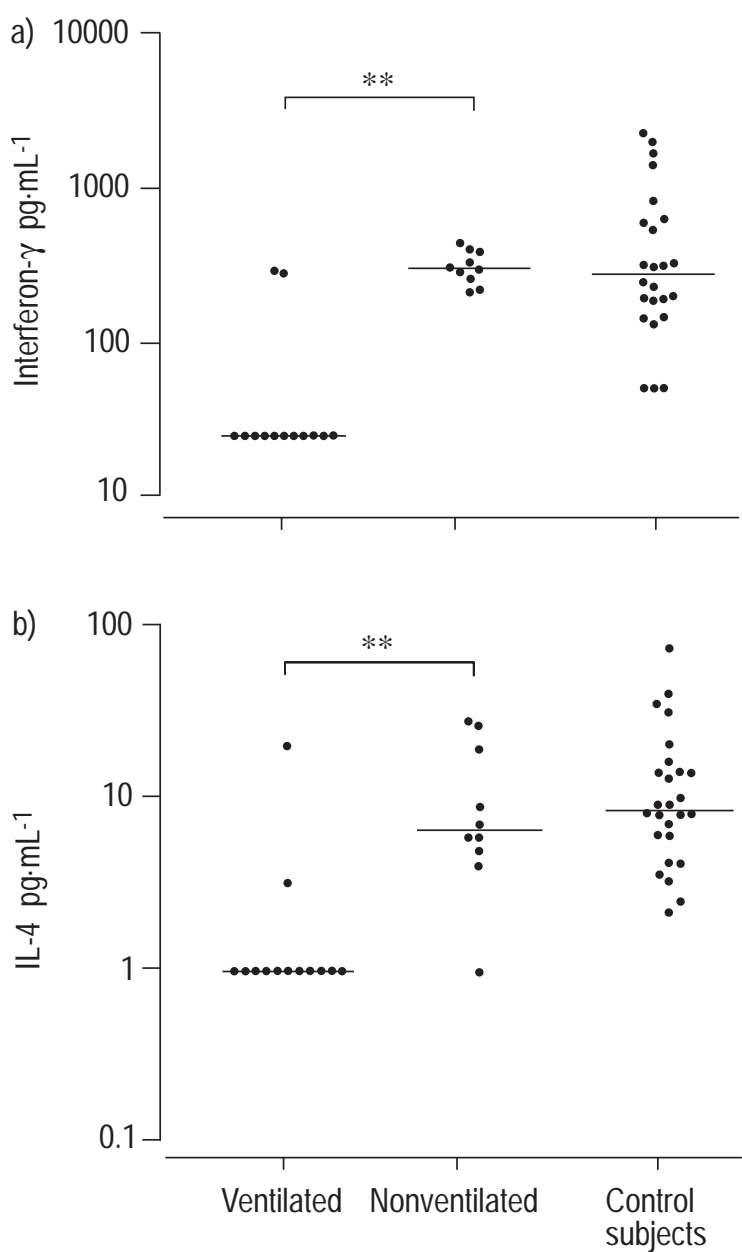

Fig. 3. - Production of a) interferon- $\gamma$ and b) interleukin (IL)-4 in 48-h phytohaemagglutinin-stimulated whole blood cultures measured within $24 \mathrm{~h}$ after admission of ventilated patients, nonventilated patients and control subjects. Bars represent mean values. ${ }^{* *}: \mathrm{p}<0.001$.

Age and maturation-related immune mechanisms could explain differences between ventilated and nonventilated patients. It is generally acknowledged that neonates can experience severe morbidity from infections with viral and other intracellular pathogens, including RSV bronchiolitis $[2,19-22]$. In the neonatal period, antiviral immunity appears to be diminished and this is accompanied by a general failure of neonatal antiviral T-cells to mature into protective virus-specific memory cells $[23,24]$. In premature neonates this maturational deficiency is even more pronounced. Severely decreased expression of the CD40 ligand on activated T-cells in neonates could play a role in this maturational failure [25]. Moreover, it was demonstrated that neonatal T-cells have a lower capacity for IFN $-\gamma$ production after polyclonal stimulation than adult T-cells [26]. This finding was confirmed in the present control group, where a significant correlation between IFN- $\gamma$ production (but not IL-4 production) and age was found. To the authors' knowledge, the development of antigen-specific immune responses in human neonates, including cytokine responses, has only been documented in neonatal herpes simplex virus (HSV) infection; during the first 3-6 weeks after delivery, diminished antigenstimulated IFN- $\gamma$ and lymphoproliferative responses were reported in HSV-infected neonates [20]. As far as RSV is concerned, in vitro studies have demonstrated that RSVinfected human adult lymphocytes show depressed proliferative responses after polyclonal stimulation [27]. Taking together these observations and the present results, it appears that RSV also suppresses neonatal lymphocyte function in vivo, preventing an adequate immune response to RSV proteins. Moreover, it is speculated that proliferation and cytokine responses in neonatal lymphocytes may be more sensitive than more mature lymphocytes to the suppressive effect of RSV. Immature antiviral immunity and increased sensitivity to suppressive influences of RSV on lymphocyte function may explain why lymphoproliferative and cytokine responses in (younger) ventilated patients are more suppressed than in nonventilated patients.

The two patient groups were distinguished by the need for mechanical ventilation. The effects of mechanical ventilation on immune responses is largely unknown, but reports in laboratory animals indicate that it can change local as well as systemic inflammatory responses [28]. As a result, a possible influence of mechanical ventilation on the immune responses of ventilated patients cannot be excluded from this study. However, samples taken in the acute phase were collected within the first $24 \mathrm{~h}$ after mechanical ventilation was initiated, in the majority of cases even within 2-6 h. To the authors' knowledge, no data are available in the literature, addressing the kinetics of immune responses during the first hours of mechanical ventilation. However, it is unlikely that mechanical ventilation-induced changes in immune responses in the current patient group during this short time interval between the initiation of mechanical ventilation and blood sampling.

Asthma is characterized by a relative increase in production of Th2 cytokines (e.g. IL-4) and a relative suppression of production of Th1 cytokines (e.g. IFN- $\gamma$ ) [15, 17]. Considering the association between RSV bronchiolitis and the subsequent development of asthma, the possible skewing of the Th1/Th2 cytokine balance was investigated by calculating IL-4/IFN- $\gamma$ ratios [29]. IL-4/ IFN- $\gamma$ ratios in both patient groups were normal in the acute and convalescent phase. However, IL-4/IFN- $\gamma$ ratios could not be calculated for ventilated patients in the acute phase. Roman et al. [13] reported increased IL-4/ IFN- $\gamma$ ratios after in vitro stimulation with pokeweed mitogen in RSV-infected children with lower respiratory tract symptoms. This apparent contradiction may be due to different culture conditions and a higher median age in their patient group.

The association found between increased plasma IL-8 levels and severe RSV bronchiolitis is similar to the findings by SHUTE et al. [30] who demonstrated an association between increased serum IL-8 levels and severe asthma. However, increased IL-8 plasma levels are not specific for RSV disease, since increased plasma IL-8 levels have been suggested to play a role in various respiratory diseases, possibly by similar mechanisms, including neutrophil and eosinophil attraction, IgE-mediated lung disease and virus-induced respiratory inflammation [4, 31-35].

During the past few decades, data have become available indicating that RSV bronchiolitis can be considered an immune-mediated disease [4]. Early trials with a formalin-inactivated RSV vaccine resulting in enhanced disease 
support this hypothesis. However, this theory does not explain the higher incidence of severe disease observed in young and/or prematurely born infants. The current findings suggest that an immunological process is not the sole factor in the pathogenesis of severe disease in RSV bronchiolitis. In young and prematurely born infants, insufficient antiviral immunity seems to play an important role, particularly with respect to disease severity.

In summary, the results have shown that suppressed lymphocyte function and increased plasma IL-8 levels are markers of severe disease in respiratory syncitial virus bronchiolitis. In addition, it is proposed that maturation of virus-specific immunity plays a crucial role in the outcome of respiratory syncitial virus infection in young infants. In order to understand the pathogenesis of respiratory syncitial virus bronchiolitis and immunological factors contributing to severity of this disease, future work needs to focus on the development of the specific immune responses to respiratory syncitial virus in preterm and term infants. Elucidating these mechanisms will be important for the development of treatment strategies and vaccines.

\footnotetext{
Acknowledgements. The authors wish to thank J. Zijlstra and M. Ringeling-Van der Pol (University Hospital for Children and Youth "Het Wilhelmina Kinderziekenhuis", Utrecht, the Netherlands) for excellent technical assistance, and C.C.H.M. Smeets (Rijnstate Hospital, Arnhem, the Netherlands) for assistance in obtaining clinical samples.
}

\section{References}

1. McDonald NE, Hall CB, Suffin SC, Alexon C, Harris PJ, Manning JA. Respiratory syncytial virus infection in infants with congenital heart disease. $N$ Engl J Med 1982: 307: $397-400$

2. Hall CB, Kopelman AE, Douglas RG, Geiman JM, Meagher MP. Neonatal respiratory syncytial virus infection. N Engl J Med 1979; 300: 393-396.

3. Opavski MA, Stephens D, Wang EEL. Testing models predicting severity of respiratory syncytial virus infections on the PICNIC RSV database. Pediatric lnvestigators Collaborative Network on Infections in Canada. Arch Pediatr Adolesc Med 1995; 149: 1217-1220.

4. Kimpen JLL. Respiratory syncytial virus immunology. Pediatr Allergy Immunol 1996; 7 (Suppl. 9): 86-90.

5. Openshaw PJM. Immunopathological mechanisms in respiratory syncytial virus disease. Springer Semin Immunopathol 1995; 17: 187-201.

6. Welliver RC, Wong DT, Sun M, Middleton EJR, Vaughan RS, Ogra PL. The development of respiratory syncytial virus-specific $\operatorname{IgE}$ and the release of histamine in nasopharyngeal secretions after infection. N Engl J Med 1981; 305: $841-846$

7. Garofalo RP, Ahlstedt DA, Welliver RC. Peripheral blood eosinophil counts and eosinophil cationic protein content of respiratory secretions in bronchiolitis: relationship to severity of disease. Pediatr Allergy Immunol 1994; 5: 111-117.

8. Graham BS, Bunton LA, Wright PF, Karzon DT. Role of $T$ lymphocyte subsets in the pathogenesis of primary infection and rechallenge with respiratory syncytial virus in mice. J Clin Invest 1991; 88: 1026-1033.

9. Hussell T, Spender IC, Georgiou A, O'Garra A, Open- shaw PJM. Th1 and Th2 cytokine induction in pulmonary T cells during infection with respiratory syncytial virus. $J$ General Virol 1996; 77: 2447-2455.

10. Connors M, Kulkarni AB, Firestone CY, et al. Pulmonary histopathology induced by respiratory syncytial virus (RSV) challenge of formalin-inactivated RSV-immunized BALB/c mice is abrogated by depletion of CD4+ T cells. J Virol 1992; 66: 7444-7450.

11. Isaacs D, Bangham CRM, McMichael AJ. Cell-mediated cytotoxic response to respiratory syncytial virus in infants with bronchiolitis. Lancet 1987; ii: 769-771.

12. Welliver RC, Kaul A, Ogra PL. Cell-mediated immune response to respiratory syncytial virus infection: relationship to the development of reactive airway disease. $J$ Pediatr 1979; 94: 370-375.

13. Roman M, Calhoun WJ, Himton KL, et al. Respiratory syn-cytial virus infection in infants is associated with predominant Th-2-like response. Am J Respir Crit Care Med 1997; 156: 190-195.

14. Isaacs D. Production of interferon in respiratory syncytial virus bronchiolitis. Arch Dis Child 1989; 64: 92-95.

15. Folkerts G, Busse WW, Nijkamp FP, Sorkness RL, Gern JE. Virus-induced airway hyperresponsiveness and asthma. Am J Respir Crit Care Med 1998; 157: 1708-1720.

16. Welliver RC, Duff AL. The relationship of RSV-specific immunoglobulin E-antibody responses in infancy, recurrent wheezing and pulmonary function at age 7-8 years. Pediatr Pulmonol 1993; 15: 19-27.

17. Umetsu DT, DeKruyff RH. Th1 and Th2 cd4+ cells in human allergic diseases. J Allergy Clin Immunol 1997; 100: $1-6$.

18. Madge P, Paton JY, McColl JH, Mackie PLK. Prospective controlled study of four infection-control procedures to prevent nosocomial infection with respiratory syncytial virus. Lancet 1992; 340: 1079-1083.

19. Wilson CB. Immunological basis for increased susceptibility of the neonate to infection. J Pediatr 1986; 108: 112.

20. Burchett SK, Corey L, Mohan KM, Westall J, Ashley R, Wilson CB. Diminished interferon-gamma and lymphocyte proliferation in neonatal and postpartum primary herpes simplex virus infection. J Infect Dis 1992; 165: 813-818.

21. Starr SE, Toplin MD, Friedman HM. Impaired cellular immunity to cytomegalovirus in congenitally infected children and their mothers. $J$ Infect Dis 1979; 140: 500505.

22. Smith S, Jacobs RF, Wilson CB. Immunobiology of childhood tuberculosis: a window on the ontogeny of cellular immunity. J Pediatr 1997; 131: 16-26.

23. Holt PG. Postnatal maturation of immune competence during infancy and childhood. Pediatr Allergy Immunol 1995; 6: 59-70.

24. Hayward AR, Groothuis JR. Development of T cells with memory phenotype in infancy. Adv Exp Med Biol 1991; 310: 71-76.

25. Nonoyama S, Penix LA, Edwards CE. Dimished expression of CD40 ligand by activated neonatal T cells. $J$ Clin Invest 1995; 95: 66-75.

26. Lewis DB, Yu CC, Meyer J, English BK, Kahn SJ, Wilson CB. Cellular and molecular mechanisms for reduced interleukin 4 and interferon gamma production by neonatal T cells. J Clin Invest 1991; 87: 194-202.

27. Roberts NJ. Different effects of influenza virus, respiratory syncytial virus, and sendai virus on human lymphocytes and macropohages. Infect Immun 1982; 35: $1142-1146$. 
28. Tremblay L, Valenza F, Ribeiro SP, Li J, Slutsky AS. Injurious ventilatory strategies increases cytokines and c-fos mRNA expression in an isolated rat model. $J$ Clin Invest 1997; 99: 944-952.

29. Sims DG, Downham MA, Gardner PS. Study of 8-yr-old children with a history of respiratory syncytial virus bronchiolitis in infancy. BMJ 1978; 1: 11-17.

30. Shute J, Vrugt B, Lindley IJD, et al. Free and complexed interleukin-8 in blood and bronchial mucosa in asthma. Am J Respir Crit Care Med 1997; 153: 1877-1883.

31. Kotecha S, Chan B, Azam N, Silverman M, Shaw RJ. Increase in interleukin-8 and soluble intercellular adhesion molecule-1 in bronchoalveolar lavage fluid from premature infants who develop chronic lung disease. Arch Dis Child 1995; 72: F90-F96.
32. Erger RA, Casale TB. Interleukin- 8 is a potent mediator of eosinophil chemotaxis through endothelium and epithelium. Am J Physiol 1995; 268: L117-L122.

33. Erger RA, Casale TB. Interleukin-8 plays a significant role in IgE-mediated lung inflammation. Eur Respir $J$ 1998; 11: 299-305.

34. Teran LM, Johnston SL, Schroder JM, Church MK, Holgate ST. Role of nasal interleukin-8 in neutrophil recruitment and activation in children with virus-induced asthma. $\mathrm{Am} J$ Respir Crit Care Med 1997; 155: 1362-1366.

35. Arnold R, Werner F, Humbert B, Werchau H, Konig W. Effect of respiratory syncytial virus-antibody complexes on cytokine (IL-8, IL-6, TNF alpha) release and respiratory burst in human granulocytes. Immunology 1994; 82: 184-191. 